\title{
Mobility and distribution of barium and strontium in profiles of podzolic soils
}

\begin{abstract}
The study was aimed at determining the content, distribution and mobility of barium and strontium in various forest podzol soils. Samples with a wide range of chemical and physical properties were collected from typical uncontaminated soils of south-western Poland. The total metal content in the analyzed soils was considered as the geochemical background thanks to the natural features of the study site. Sequential chemical extraction procedure were used to provide information on the mobility and bioavailability of the studied metals in the soil. Fractions of $\mathrm{Ba}$ and $\mathrm{Sr}$ were determined using the five-step procedure of Tessier et al. (1979). The results show that heavy metals were generally represented by the exchangeable fraction (F1 - barium) and the residual fraction (F5 - strontium) with the average values at 53 and 69\%, respectively. The mobility of barium in all soil profiles was very high, ranging within 52-54\% and indicating a generally high availability and mobility. Relatively very low levels of the trace elements were found in the fraction bound to organic matter (F4: 3-8\%). Very low levels of strontium were found also in the fraction bound to carbonates (F2: 2-3\%). Humic-eluvial, illuvial and sideric horizons were enriched in the fractions of barium and strontium bound to iron and manganese oxides (F3).
\end{abstract}

Key words: barium, strontium, sequential analysis, soil

\section{INTRODUCTION}

The content of heavy metals in soils of Poland is very variable. This results from the regional occurrence of the sources of these elements, which are represented by industrial emission, industrial and municipal wastes, motorization, traffic infrastructure and mining exploitation, characterized by a long-term influence on the environment. Therefore, the knowledge on the natural contents of heavy metals in soils plays a significant role in assessing the condition of the soil environment and interpretation of potential pollution causes. Natural contents of heavy metals in soils depend mainly on the type of the parent rock, intensity of weathering of the substrate and its geochemical composition, as well as the trends of the pedogenic processes.

Barium and strontium are easily leached downward the soil profiles, particularly in light acidic soils, and may be concentrated in the soil sub-surface levels (Kabata-Pendias and Pendias, 1993), therefore the identification of their fractions in soils is very important. These oxyphilic group 2a elements comprising alkaline earth metals are the most common trace elements in soils. Barium and strontium are geochemically similar, however each element has its own, specific properties. Strontium occurs in numerous minerals: calcium, fluorite, calcareous zeolites, as well as barium minerals (barite, witherite). The similarity of both elements is the result of comparable ionic radiuses. However, comparison of the geochemistry of barium and strontium indicates a lower mobility of barium.

The ionic radius of barium favours its binding with potassium; in magmatic rocks it is often accumulated in acidic, high-potassium and alkaline rocks. Weathering of the rock-forming minerals results in passing of strontium into the soil solution and surface waters in form of complex compounds, carbonates, chlorides or sulphates (Polański and Smulikowski, 1969).

This paper presents the distribution of the total content and fractions of barium and strontium in the natural genetic horizons of selected soils.

\section{MATERIAL AND STUDY METHODS}

Soil samples were collected from characteristic genetic horizons of podzol soils (Haplic Podzols - 2 profiles, Dystric Brunic Arenosol - 1 profile, Albic Brunic Arenosol - 1 profile). The study area was located in forests of the Turawa Forest Division, where the soils are linked mainly with coniferous forests 
(mixed fresh coniferous forest and fresh coniferous forest). The terms used for particular soils are in accordance with the Classification of the Forest Soils of Poland (2000) and the World Reference Base for Soil Resources (IUSS Working Group WRB, 2006).

Forests of the Turawa Forest Division are located administratively in the Opole province, Opole County. The forests are located in the Silesian (V) Region, Opole Plain District, Bory Stobrawskie Mesoregion (Trampler et al. 1990). The location of the study area excludes the direct pollution of the soils from industrial, communication or municipal sources. The particular metal fractions were determined using the fivestage procedure of Tessier et al. (1979) in order to assess what soil components are barium and strontium bound with in the soil profiles that are not subject to anthropopression. The following properties were determined in the samples: grain size composition (Casagrande method in the modification of Prószyński), $\mathrm{pH}$ (potentiometer method), and organic carbon content (elemental analysis method). The total content of the elements in the solutions was detected using the ICP-AES method after mineralization in concentrated $\mathrm{HCl}$ and $\mathrm{HNO}_{3}$ acids.

\section{RESULTS}

The common properties of the studied soils were the type of parent material, similar land management (forests) and similar pedogenic conditions. On diverse sedimentary rocks occurring in Poland, sedimen- tary processes lead to the formation of soils characterized by variable grain size, various composition and different contents of particular elements (CzępińskaKamińska, 1992). Data on the basic properties of the studied soils are presented in Table 1.

Podzols are characterized by relatively low grain size variability within the profiles. The determined grain size composition has allowed to classify the studied soils as sands. The parent rock was loose sand, slightly clayey sand or silty, strongly clayey sand. The sand fraction in the analyzed soils is dominated by the sub-fractions of medium and fine sands, whose percentage content was: $24-46$ and $20-53 \%$, respectively. The studied soils are characterized by a low percentage content of the silt fraction $(\varnothing 0.1-0.02)$, whose content was within 3-30\%, with an average at $14.63 \%$ (Table 1). The percentage content of the $\varnothing<0.02$ fraction was from 1 to $6 \%$, with an average at $7.59 \%$. The reaction of the studied soils was from very strongly acidic $(\mathrm{pH}$ in $\mathrm{KCl}<3.5)$ to strongly acidic ( $\mathrm{pH}$ in $\mathrm{KCl} 3.6-4.5)$. Sub-surface horizons were typically more acidic than the lower lying genetic horizons. The average content of organic carbon in the organic fermentative-humic horizons $(\mathrm{Ol}+\mathrm{Ofh})$ of the studied soils was $26.46 \%(21.15-30.91 \%)$. The distribution of organic carbon in particular genetic horizons has indicated a natural diversity between the humic and mineral horizons (Table 1).

Ranges of the total contents ( $\Sigma \mathrm{F} 1-\mathrm{F} 5)$ of barium and strontium in soils were at: $14.80-38.20$ and $1.96-4.79 \mathrm{mg} \cdot \mathrm{kg}^{-1}$, respectively (Table 2 ). Arithme-

TABLE 1. Physicochemical properties of the analyzed soils

\begin{tabular}{|c|c|c|c|c|c|c|c|c|}
\hline \multirow[t]{2}{*}{$\begin{array}{l}\text { Profile number and } \\
\text { soil type }\end{array}$} & \multirow[t]{2}{*}{$\begin{array}{l}\text { Genetic } \\
\text { horizon }\end{array}$} & \multirow[t]{2}{*}{$\begin{array}{l}\text { Depth } \\
\text { [cm] }\end{array}$} & \multirow[t]{2}{*}{$\begin{array}{l}\mathrm{C} \\
{[\%]}\end{array}$} & \multirow[t]{2}{*}{$\begin{array}{l}\mathrm{pH} \\
\mathrm{H}_{2} \mathrm{O}\end{array}$} & \multirow[t]{2}{*}{$\begin{array}{l}\mathrm{pH} \\
\mathrm{KCl}\end{array}$} & \multicolumn{3}{|c|}{$\begin{array}{l}\text { Percentage of fraction with diameter } \\
\text { in } \mathrm{mm}\end{array}$} \\
\hline & & & & & & $1-0.1$ & $0.1-0.02$ & $<0.02$ \\
\hline Profile 1 & Ofh & $0-5$ & 21.15 & 4.37 & 3.79 & - & - & - \\
\hline \multirow{4}{*}{ Typic podzol soil } & AEes & $5-15$ & 1.03 & 4.04 & 3.80 & 79 & 11 & 10 \\
\hline & $\mathrm{B}(\mathrm{h}) \mathrm{fe}$ & $15-33$ & 0.00 & 4.44 & 4.10 & 93 & 6 & 1 \\
\hline & $\mathrm{C}$ & $33-100$ & 0.03 & 4.14 & 3.90 & 95 & 3 & 2 \\
\hline & $\mathrm{CG}$ & $100-160$ & 0.00 & 4.05 & 3.70 & 87 & 6 & 7 \\
\hline Profile 2 & $\mathrm{OH}+\mathrm{Ofh}$ & $0-3$ & 26.98 & 3.74 & 3.06 & - & - & - \\
\hline \multirow[t]{6}{*}{ Typic podzol soil } & $\mathrm{Ah}$ & $3-7$ & 3.68 & 3.61 & 2.91 & 87 & 10 & 3 \\
\hline & AEes & $7-20$ & 1.10 & 3.44 & 2.80 & 87 & 10 & 3 \\
\hline & $\mathrm{Bh}$ & $20-23$ & 1.65 & 3.83 & 3.33 & 80 & 16 & 4 \\
\hline & $\mathrm{Bfe}$ & $23-36$ & 0.55 & 4.23 & 4.12 & 85 & 12 & 3 \\
\hline & $\mathrm{C}$ & $36-72$ & 0.00 & 4.43 & 4.21 & 75 & 21 & 4 \\
\hline & CGor & $72-125$ & 0.02 & 3.92 & 3.75 & 53 & 31 & 16 \\
\hline Profile 3 & $\mathrm{Ol}+\mathrm{Ofh}$ & $0-5$ & 22.83 & 4.04 & 3.10 & - & - & - \\
\hline \multirow[t]{3}{*}{ Proper rusty soil } & $\mathrm{Abv}$ & $5-19$ & 0.76 & 3.92 & 3.62 & 93 & 4 & 3 \\
\hline & $\mathrm{Bv}$ & $19-45$ & 0.18 & 4.31 & 4.34 & 95 & 4 & 1 \\
\hline & $\mathrm{C}$ & $45-140$ & 0.00 & 4.44 & 4.45 & 95 & 4 & 1 \\
\hline Profile 4 & $\mathrm{Ol+Ohf}$ & $0-4$ & 30.91 & 3.74 & 2.89 & - & - & - \\
\hline \multirow[t]{3}{*}{ Podzolized rusty soil } & AEes & $4-12$ & 0.79 & 4.01 & 3.45 & 93 & 4 & 3 \\
\hline & BvBhfe & $12-53$ & 0.41 & 4.24 & 4.15 & 93 & 5 & 2 \\
\hline & $\mathrm{C}$ & $53-120$ & 0.00 & 4.33 & 4.25 & 95 & 5 & 0 \\
\hline
\end{tabular}


TABLE 2. Range, mean and standard deviation of the total metal content in the diagnostic soil horizons

\begin{tabular}{lll}
\hline Genetic horizon & \multicolumn{2}{l}{$\begin{array}{l}\text { Range, mean }( \pm \text { SD) of total metal } \\
\text { content in diagnostic soil horizons }\end{array}$} \\
\cline { 2 - 3 } & barium & strontium \\
\hline Humus horizons & $15.60-30.50$ & $2.39-3.98$ \\
& 21.00 & 3.21 \\
& \pm SD 6.23 & \pm SD 0.57 \\
\hline Humus-illuvial & $14.80-22.20$ & $1.96-3.13$ \\
and rusty horizons & 19.28 & 2.66 \\
& \pm SD 2.87 & \pm SD 0.50 \\
\hline Parent material & $15.70-38.20$ & $2.56-4.79$ \\
horizons & 22.47 & 3.43 \\
& \pm SD 9.02 & \pm SD 1.00 \\
\hline
\end{tabular}

tic means of the analyzed elements in the diagnostic genetic horizons are presented in Table 2. The remaining statistic parameters are shown in Table 4.

The mean content of barium and strontium in soils of the world according to USEPA data reaches $430.00(200-1000)$ and $200.00 \mathrm{mg} \cdot \mathrm{kg}^{-1}(5-1000$ $\left.\mathrm{mg} \cdot \mathrm{kg}^{-1}\right)$, respectively, but the total contents of the elements vary within a very wide range, depending on the type of the parent rock and type of soil. The mean content of strontium in the podzols of Poland is $14-93 \mathrm{mg} \cdot \mathrm{kg}^{-1}$ and of barium $-85-410 \mathrm{mg} \cdot \mathrm{kg}^{-1}(\mathrm{Ka}-$ bata-Pendias and Pendias, 1993). None of these values was exceeded and the obtained results indicate that the measured values represent the background.

The percentage contribution of the analyzed elements in the fractions was calculated in relation to the sum of all fractions ( $\mathrm{F} 1-\mathrm{F} 5)$. Regardless the genetic horizon, barium dominated in the exchangeable fraction (F1). In the humus, mineral and parentrock horizons, its percentage contribution in the exchangeable fraction was: 40,36 and $33 \%$, respectively, in relation to the total content of this element, calculated as the sum of all fractions. The mean per- centage contribution of the mobile fractions of barium was $53 \%$ in relation to the total content of this metal. The mean content of barium in the fraction bound to iron and manganese oxides and in the residual fraction was 18 and $24 \%$, respectively. The content of barium in the fraction bound to iron and manganese oxides decreased, whereas the content of this element in the residual fraction increased with the profile depth. Regardless the genetic horizon, strontium dominated in the residual fraction, where its contribution in relation to the sum of all fractions was $65-76 \%$. The sum of the mobile fractions of strontium was $12-20 \%$ in relation to the total content of this metal and decreased with the profile depth. The mean content of strontium in the fraction bound to organic matter and the fraction bound to iron and manganese oxides did not exceed $7 \%$ in both cases.

\section{DISCUSSION}

The geochemical properties of the studied metals and their occurrence in the natural environment in form of oxides, silicates and other salts of oxygen acids result in the highest mean values of the analyzed metals in the parent rock horizons of the soil. Dimensions of atoms of barium and strontium are close to the dimensions of hydrated ions, which may favour strong binding of these elements with the soil solid phase and thus their domination in the soil residual fraction (F5). This is evidenced by the fact that strontium, regardless the genetic horizon, dominated in the residual fraction (F5). Barium had high mobility in all analyzed genetic horizons of the studied podzols. According to Pichtel et al. (2000), barium occurred mainly in the residual fraction, where it reached averagely $46.8 \%$. Our studies did not confirm the general statement of low barium mobility.

TABLE 3. Mean content ( \pm SD) of barium and strontium fractions in the analyzed soils assessed with the Tessier et al. (1979) procedure

\begin{tabular}{lllllll}
\hline \multirow{2}{*}{ Genetic horizon } & \multicolumn{5}{l}{ Metal fractions $\left(\mathrm{mg} \cdot \mathrm{kg}^{-1} \mathrm{~s} . \mathrm{m}\right)$} \\
\cline { 2 - 7 } & $\mathrm{F} 1$ & $\mathrm{~F} 2$ & $\mathrm{~F} 3$ & $\mathrm{~F} 4$ & $\mathrm{~F} 5$ & $\Sigma(\mathrm{F} 1-\mathrm{F} 5)$ \\
\hline Barium & & & & & \\
\hline AEes, Ah, AEes, Abv & $8.32 \pm 4.90$ & $2.50 \pm 0.73$ & $4.32 \pm 1.56$ & $1.78 \pm 1.11$ & $4.08 \pm 1.80$ & $21.00 \pm 6.23$ \\
Bhfe, Bh, Bfe & $7.97 \pm 1.64$ & $3.60 \pm 0.85$ & $3.97 \pm 1.26$ & $0.77 \pm 0.21$ & $4.47 \pm 0.49$ & $20.77 \pm 1.76$ \\
Bv & $5.75 \pm 1.77$ & $3.15 \pm 0.78$ & $3.60 \pm 0.14$ & $0.65 \pm 0.07$ & $3.90 \pm 0.42$ & $17.05 \pm 3.18$ \\
C,CG & $7.53 \pm 2.21$ & $4.63 \pm 2.59$ & $2.88 \pm 1.07$ & $0.72 \pm 0.21$ & $6.70 \pm 3.80$ & $22.47 \pm 9.02$ \\
\hline Strontium & & & & & \\
\hline AEes, Ah, AEes, Abv & $0.57 \pm 0.49$ & $0.07 \pm 0.02$ & $0.23 \pm 0.04$ & $0.26 \pm 0.04$ & $2.07 \pm 0.78$ & $3.21 \pm 0.51$ \\
Bhfe, Bh, Bfe & $0.41 \pm 0.21$ & $0.11 \pm 0.02$ & $0.21 \pm 0.07$ & $0.17 \pm 0.03$ & $1.83 \pm 0.15$ & $2.73 \pm 0.36$ \\
Bv & $0.24 \pm 0.10$ & $0.07 \pm 0.03$ & $0.25 \pm 0.11$ & $0.19 \pm 0.02$ & $1.80 \pm 0.57$ & $2.55 \pm 0.83$ \\
C,CG & $0.33 \pm 0.14$ & $0.07 \pm 0.03$ & $0.20 \pm 0.07$ & $0.20 \pm 0.02$ & $2.63 \pm 0.92$ & $3.43 \pm 1.00$ \\
\hline
\end{tabular}


Similar results with regard to strontium (determined using the Tessier et al. 1979 procedure) have been obtained by Madeyski et al. (2009). The studies have shown that strontium dominated mainly in the residual fractions and the sum of the mobile fractions did not exceed $11 \%$ with regard to the total content of this element. In the analyzed podzols, the sum of all mobile fractions of strontium varied within $12-20 \%$. Despite the significant contribution of strontium in the residual fraction, both elements belonging to alkaline earth metals showed a trend to accumulate in large quantities in the exchangeable fraction, despite the genetic horizon, soil type and localization. This is not favourable with regard to the ecology and environmental protection, as both elements may pass into the soil solution. Despite the geochemical similarity of the two elements, barium is more mobile than strontium in light sandy soils. When analyzing barium fractions, Reddy et al. (2010) also showed that this element dominates mainly in the soil residual fraction (F5). According to Magalhăes et al. (2012), the final results are largely influenced by the reagents used in sequential analysis, which have strongly reductive properties, as well as the reduction potential (F3). Moreover, these authors have shown that the content of barium in the mobile fractions increased in favour of the fractions bound to iron and manganese oxides. Iron and manganese oxides are dissolved in reductive conditions, resulting in the release of barium and strontium ions earlier bound with these minerals to the soil solution. This process explains the high percentage content of this element in the exchangeable fraction. Barium is easily released during weathering processes and then precipitated in form of carbonates and sulphates, which may also influence the obtained results. The considerable content of barium in the residual fraction and in the fraction bound to iron and manganese oxides in the analyzed soils may result from the strong binding of the element by clay minerals and iron-manganese concretions (Pasieczna, 2003; Kabata-Pendias and Pendias, 1993; Pichtel, 2000; Vodyanitskii et al., 2010), particularly in the humus-elluvial, illuvial and rusty horizons of the podzols. Strontium and barium are transported downward the soil profile or accumulated in the sub-surface soil horizons, which is reflected in the obtained results. The process is particularly common in acidic conditions, causing that the high average sum of fractions (F1-F5) was noted in the parent rock, humus-elluvial horizons of Haplic Podzols and Albic Brunic Arenosol (profiles 1,2 and 4) and sideric horizons of Dystric Brunic Arenosol (profile 3) where the $\mathrm{pH}$ values were the lowest. Barium and strontium undergo easy sorption on organic mat-

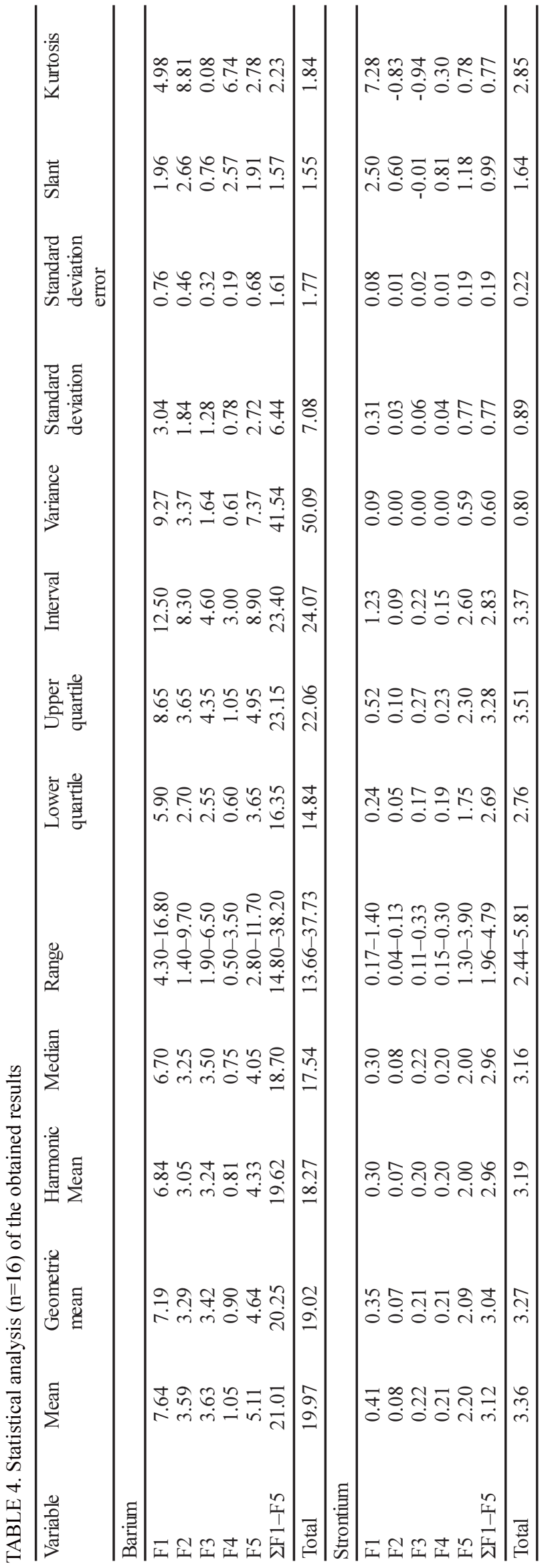


ter, therefore in the humus and elluvial-humus horizons rich in organic matter the contribution of both elements is the highest in the fraction bound to organic matter (Table 3). However, due to restricted complexing by organic matter, the contents of both elements do not exceed several percents in the fraction bound to organic matter. A similar relationship was observed by Pichtel et al. (2000), where the content of barium in the fraction bound to organic matter did not exceed $3.2 \%$.

The basic statistic parameters were also calculated (Table 4). The analysis indicated that there were no marginal values that could influence their variability. The mean total content, sum ( $\Sigma \mathrm{F} 1-\mathrm{F} 5)$ and content of the element in particular fractions was significantly higher for barium than for strontium. Additionally, the total variability area of the analyzed data was larger for barium than for strontium. Results for strontium were more concentrated around the medium value than the results for barium. However, concentration near the average for both elements indicated that most parameters (excluding the results for strontium fractions F2 and F3) had a 'slender' distribution.

The calculated correlation coefficients (Table 5) point to a significant positive relationship between the grain size composition of the studied soils and the content of barium in fractions F2, F3 and F5 and sum of all fractions ( $\Sigma F 1-F 5)$ (Table 3$)$. The occurrence of barium in the organic fraction (F4), in the fraction bound to iron and manganese oxides (F3) and the exchangeable fraction (F1) was positively correlated with the organic carbon content. The occurrence of barium in the exchangeable fraction was significantly negatively correlated with $\mathrm{pH}(\mathrm{KCl})$ of the analyzed soils. The total content of barium in the studied soils was significantly correlated with the content of the silt, sand and floatable fractions. A larger content of the floatable fraction resulted in the larger content of barium in the residual fraction (F5). Positive significant correlation coefficients were noted between the organic carbon content and the occurrence of strontium in the exchangeable fraction (F1) and in the fraction bound to organic matter (F4). The occurrence of strontium in the exchangeable fraction (F1), similarly as in the case of barium, was significantly negatively correlated with $\mathrm{pH}(\mathrm{KCl})$. A statistically significant relationship between the sand and silt fraction and the occurrence of strontium in the fractions bound to iron and manganese oxides (F3) was also noted. The total content of strontium ( $\mathrm{F} 1-\mathrm{F} 5)$ and barium was higher with increase of the sand and grains $\varnothing<0.02$ fractions content. Such relationship was not observed in the case of the silt fraction (Table 5).
TABLE 5. Correlation coefficient between the soil properties and the heavy metal fractions analyzed with the Tessier et al. (1979) procedure

\begin{tabular}{|c|c|c|c|c|c|}
\hline \multirow[t]{3}{*}{ Fractions } & \multicolumn{5}{|c|}{ Soil properties } \\
\hline & \multirow{2}{*}{$\begin{array}{l}\mathrm{pH} \\
\mathrm{KCl}\end{array}$} & \multirow{2}{*}{$\begin{array}{l}\text { Corg } \\
\text { content }\end{array}$} & \multicolumn{3}{|c|}{ texture with diameter in $\mathrm{mm}$} \\
\hline & & & $1-0.1$ & $0.1-0.02$ & $<0.02$ \\
\hline \multicolumn{6}{|l|}{ Barium } \\
\hline F1 & $-0.53 *$ & $0.66^{* *}$ & -0.28 & 0.31 & 0.20 \\
\hline F2 & 0.18 & -0.28 & $-0.73^{* *}$ & $0.65 * *$ & $0.71 * *$ \\
\hline F3 & -0.28 & $0.57 *$ & $-0.50^{*}$ & 0.46 & $0.52 *$ \\
\hline F4 & -0.41 & $0.58^{*}$ & -0.24 & 0.14 & 0.44 \\
\hline F5 & 0.08 & -0.35 & $-0.64 * *$ & 0.48 & $0.81 * *$ \\
\hline$\Sigma \mathrm{F} 1-\mathrm{F} 5$ & -0.27 & 0.27 & $-0.74 * *$ & $0.64 * *$ & $0.79 * *$ \\
\hline \multicolumn{6}{|l|}{ Strontium } \\
\hline F1 & $-0.73 * *$ & $0.84 * *$ & -0.03 & 0.06 & -0.02 \\
\hline $\mathrm{F} 2$ & -0.34 & 0.37 & -0.16 & 0.13 & 0.14 \\
\hline F3 & 0.22 & 0.09 & $0.52 *$ & $-0.51 *$ & -0.47 \\
\hline F4 & -0.39 & $0.55^{*}$ & 0.20 & -0.25 & -0.01 \\
\hline F5 & 0.15 & -0.38 & $-0.59 *$ & 0.42 & $0.80 * *$ \\
\hline$\Sigma F 1-F 5$ & -0.15 & 0.00 & $-0.56 *$ & 0.39 & $0.76^{* *}$ \\
\hline
\end{tabular}

Explanations: * Significant differences at $\mathrm{p}=0.05 . *$ Significant differences at $\mathrm{p}=0.01$.

\section{CONCLUSIONS}

1. The studied forest soils are assigned to soils with a natural content of barium and strontium. The geochemical background ( $\left.\mathrm{mg} \cdot \mathrm{kg}^{-1}\right)$ of barium and strontium in the studied soils expressed as the sum of five analyzed fractions ( $\Sigma F 1-F 5)$ is $14.80-38.20$ and $1.96-4.79$, respectively.

2. Regardless the analyzed genetic horizon, barium prevails in the exchangeable fraction and strontium - in the residual fraction of light acidic podzols.

3. Barium shows strong mobility within all analyzed soil profiles. The content of barium in fractions considered as potentially bioavailable $(\mathrm{F} 1+\mathrm{F} 2)$ is $52-54 \%$ in relation to the sum of all fractions. The occurrence of barium in the exchangeable fraction depends on the organic carbon content (strong positive correlation) and $\mathrm{pH}(\mathrm{KCl})$ (strong negative correlation).

4. The humus-elluvial, illuvial and sideric (weathering) horizons are significantly enriched in barium and strontium in the fraction bound to iron and manganese oxides (F3). 


\section{REFERENCES}

Czępińska-Kamińska D., 1992. Wpływ procesów glebotwórczych na rozmieszczenie mineralnych związków fosforu w glebach. Wyd. SGGW.

IUSS Working Group WRB, 2006. World reference base for soil resources. First update 2007, 2nd ed. World Soil Resources Reports, 103. FAO, Rome: p. 128.

Klasyfikacja gleb leśnych Polski, 2000. Praca zbiorowa. Zespół Klasyfikacji Gleb Leśnych, Warszawa.

Kabata-Pendias A., Pendias H., 1993. Biogeochemia pierwiastków śladowych. Wyd. Nauk. PWN, Warszawa: 117-125 pp.

Madeyski M., Tarnawski M., Jasiewicz C., Baran A., 2009. Fractionation of chosen heavy metals in bottom sediments of smallwater reservoirs. Arch. Environ. Prot. 35(3): 47-57.

Magalhăes M.O.L., Sobrinho N.M.B.D.A., Zonta E., Carvalho M.M.D., Tolon-Becerra A., 2012. Effect of variations in the redox potential of Gleysol on barium mobility and absorption in rice plants. Chemosphere. 89(1): 121-127.

Pasieczna A., 2003. Atlas of urban soils contamination in Poland. Państwowy Instytut Geologiczny.
Pichtel J.K., Kuroiwa., Sawyerr H.T., 2000. Distribution of Pb, $\mathrm{Cd}$ and $\mathrm{Ba}$ in soils and plants of two contaminated sites. Environ. Pollut. 110: 171-178.

Polański A., Smulikowski K., 1969. Geochemia. Wyd. Geologiczne: 117-125.

Reddy K.R., Danda S., Yukselen-Aksoy Y. and Al-Hamdan A.Z., 2010. Sequestration of heavy metals in soils from two polluted industrial sites: implications for remediation. Land Contamination \& Reclamation 18(1): 13-23.

Tessier A., Campbell P.G.C, Bisson M., 1979. Sequential extraction procedure for the speciation of particular trace elements. Anal. Chem. 5: 884-850.

Trampler T., Kliczkowska A., Dmyterko E., Sierpińska A., 1990. Regionalizacja przyrodniczo- leśna na podstawach ekologiczno-fizjograficznych. PWRiL Warszawa.

Vodyanitskii Y.N., Savichev A. T., A.A. Vasilev E.S., Lobanova E.S., Chashchin A.N., Prokopovich E.V., 2010. Contents of Heavy Alkaline Earth (Sr, Ba) and Rare Earth (Y, La, Ce) Metals in Technogenically Contaminated Soils. Eurasian Soil Sci. 43(7): 822-832.

Received: November 26, 2012

Accepted: April 12, 2013 